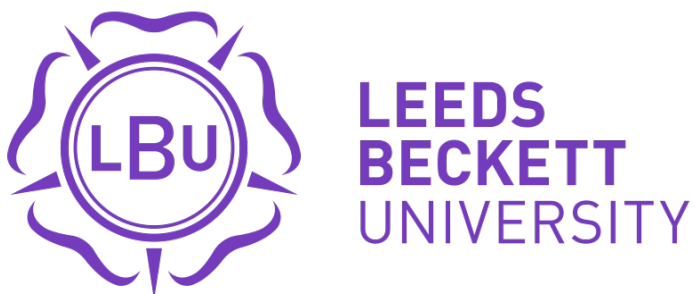

Citation:

Abraham, A (2014) Professionalism, Golf Coaching and a Master of Science Degree: A commentary. International Journal of Sports Science \& Coaching, 9 (4). 923 - 926 (4). ISSN 1747-9541 DOI: https://doi.org/10.1260/1747-9541.9.4.717

Link to Leeds Beckett Repository record:

https://eprints.leedsbeckett.ac.uk/id/eprint/174/

Document Version:

Article (Published Version)

The aim of the Leeds Beckett Repository is to provide open access to our research, as required by funder policies and permitted by publishers and copyright law.

The Leeds Beckett repository holds a wide range of publications, each of which has been checked for copyright and the relevant embargo period has been applied by the Research Services team.

We operate on a standard take-down policy. If you are the author or publisher of an output and you would like it removed from the repository, please contact us and we will investigate on a case-by-case basis.

Each thesis in the repository has been cleared where necessary by the author for third party copyright. If you would like a thesis to be removed from the repository or believe there is an issue with copyright, please contact us on openaccess@leedsbeckett.ac.uk and we will investigate on a case-by-case basis. 


\title{
Professionalism, Golf Coaching and a Master of Science Degree:
}

\author{
A Commentary \\ Andy Abraham \\ Carnegie School of Sport, Leeds Beckett University, \\ Leeds, LS6 3QT, UK \\ E-mail: A.Abraham@leedsbeckett.ac.uk
}

\section{INTRODUCTION}

As a point of reference I congratulate Simon Jenkins on tackling the issue of professionalism in coaching. As he points out coaching is not a profession, but this does not mean that coaching would not benefit from going through a professionalization process.

As things stand I find that the stimulus article unpacks some critically important issues of professionalism, broadly within the context of golf coaching. However, I am not sure enough is made of understanding what professional (golf) coaching actually is nor how the development of a professional golf coach can be facilitated by a Master of Science Degree (M.Sc.). I will focus my commentary on these two issues.

\section{PROFESSIONAL JUDGEMENT AND DECISION MAKING}

There remains a philosophical debate about what coaching is [1], but one of the more current views is to view professional coaching through the lens of decision making. This view draws on the judgement based decision-making work of Gary Klein and colleagues and Daniel Kahneman and colleagues (see [2] for an overview). Kahneman argues that judgements are made either through an intuitive, fast, Type 1 process, or through a more considered, slow Type 2 process. He goes on to argue that the vast majority of decisions are made through the Type 1 process since this is typically the most efficient in terms of using mental and time resources to solve problems and achieve goals [2]. Klein's own work reflects this general dichotomy, but he has focused on the fast Type 1 process. Klein refers to this DM process as Naturalistic Decision Making (NDM).

While there is some disagreement about specific application of DM theory to professions, both Kahneman and Klein agree that expertise in a profession can be defined through DM processes. This is an important point since it offers both a view on what coaching is (an ontological question) and of how we should investigate the practice and development of coaching (an epistemological method).

With my colleague Dave Collins, I have put forward a conceptual view on coaching that draws on the work of Kahneman and Klein, called Nested DM [3]. We argue that there are times that coaches should be more thoughtful (we call this Classical Decision Making CDM) such as at times of critical long-term planning and reflection. Equally there are times when a coach needs to make a quick judgement in time pressured coaching interventions such as feedback during a drill or a half time team talk in a match - NDM. Our argument is that these decisions should be linked (nested) in that they are targeted to achieving defined 
goals. I have tried to, simplistically ${ }^{1}$, summarise this in Table 1, along with links with other views on professional practice from researchers in reflective practice such as Schön [4].

Table 1. An Attempt to Synthesise Similarities of Views on Professional Practice as Applied to a Typical View on Coaching

\begin{tabular}{llll} 
Conceptual/Theoretical View & Process & & \\
\hline Typical Coaching View & Plan & Do & Review \\
\hline PJDM View & CDM & NDM & CDM \\
\hline Problem Solving System View & Type 2 & Type 1 & Type 2 \\
\hline Reflective Practice View & Reflection for practice & Reflection in practice & Reflection on practice \\
\hline Knowledge Source & $\begin{array}{l}\text { Formal explicit cognitive } \\
\text { structures and heuristics }\end{array}$ & $\begin{array}{l}\text { Intuitive (sometime } \\
\text { implicit) answers and } \\
\text { context specific heuristics }\end{array}$ & $\begin{array}{l}\text { Formal explicit cognitive } \\
\text { structures and heuristics }\end{array}$ \\
\hline
\end{tabular}

The ideas included in Table 1 would offer a starting point to examine golf coaching through a task analysis [5] approach that examines; what decisions coaches make, how they make them, how this changes based on context, what knowledge they draw on and how they get better at all of these tasks. Generic peer-reviewed conceptual and empirical views on coaching practice are available. Furthermore, golf coach biographies are obviously in existence, and these should not be ignored. However, I am unaware of an in-depth task analysis of coaching practice in golf. Without it there is a danger that, as educators we do not practice what we preach by making educational decisions that fail to draw on an evidence base.

\section{CREAting a postgraduate course that meEts the NEEDS OF COACHES}

It is important that research examining expert golf coaching is completed to truly get a sense of the professional development needs of golf coaches. However, and at the risk of contradicting myself, professional development courses often cannot wait while this happens. As such those engaged in the development of Masters courses that have very clear goals of professional development have to make informed decisions based on the evidence and theory available to them. We have already been through this process twice at Leeds Metropolitan University, once for an M.Sc. in Sport Coaching (i..e, 180 credits) written broadly to meet the needs of coaches working in talent development settings and once for a Post Graduate Certificate (i.e., 60 credits) written specifically for coach educators employed by The Football Association ${ }^{5}$. We have written about this approach in both cases $[6,7]$.

In both cases we were guided by two broad theoretical concepts; Biggs' concept of constructive alignment $[8,9]$ and our own model of Coach (or Coach Developer) DM [10, p. 95]. The constructive alignment model identifies six stages of development with processes 1-5 being underpinned by a thorough analysis of relevant external standards - process 6 (see Table 2).

\footnotetext{
${ }^{1}$ And this is very simplistic - I fully recognize and have written about the randomness of situations that coaches sometimes come across and have to deal with [3].
} 
Table 2. Constructive Alignment Model

1 Programme Outcomes

2 Coach capabilities to be developed

3 Assessment framework

4 Curriculum and learning activities

5 Packaging of learning into unit/modules
6 External standards; e.g., Market research, coach needs, relevant coach research, educational and institutional policy, etc.

Far from being a linear process, it is an iterative feed forward and backward process. That said, Biggs would suggest 1, 2, and 6 are thoroughly engaged in before 3, 4 and 5 are attempted. Experience of programme development would tell me, however, that the opposite approach is typically true of course design - too often I have seen courses designed by module name without sufficient consideration of what the course is trying to achieve. This has, in my opinion, led to sub optimum (irrelevant in some cases) course curriculum, delivery and assessment approaches.

The stimulus article identifies that broad curriculum discussions can be had around Shulman's [11] ideas of Content knowledge, Pedagogical knowledge and Pedagogical Content knowledge. However, more recent work in the domain of coaching has offered additional views on the knowledge that coaches need. Côté and Gilbert [12] refer to Professional Knowledge, Interpersonal Knowledge and Intrapersonal Knowledge as being the key knowledge domains used in coaching. With colleagues, I have offered and used six interconnected domains of knowledge; Knowledge and Understanding (K\&U) of the Person being 'coached', K\&U of the Topic/Sport being coached, K\&U of Pedagogy, K\&U of Coaching Process, $\mathrm{K} \& \mathrm{U}$ of the Context and Culture of the Coaching Environment, and $\mathrm{K} \& \mathrm{U}$ of Self $[6,7]$. Neither the work of Côté nor Abraham have significant empirical research to support their claims, but both offer an informed view on this area that should be considered in the development of a Master of Science degree in Golf Coaching.

\section{CONCLUSION}

There is much to applaud in Simon Jenkins' article regarding the discussion of philosophical and practical issues of professionalism in and professionalization of golf coaching. However, I feel there was a weakness in addressing some of the practicalities of developing Master of Science degree that meets the professional development needs and wants of golf coaches. I have offered some ideas to address some of these weaknesses.

\section{REFERENCES}

1. North, J., Philosophical Underpinnings of Coaching Practice Research, Quest, 2013, 65(3), 278-299.

2. Kahneman, D. and Klein, G.A., Conditions for Intuitive Expertise: A Failure to Disagree, American Psychologist, 2009, 64(6), 515-526.

3. Abraham, A. and Collins, D., Taking the Next Step: Ways Forward for Coaching Science, Quest, 2011,63(4),366-84.

4. Schön, D.A., The Reflective Practitioner: How Professionals Think in Action, Ashgate, London, 1991.

5. Klein, G. and Militello, L.. The Knowledge Audit as a Method for Cognitive Task Analysis, in: Montgomery, H., Lipsitz, R. and Brehmer, B., eds., How Professionals Make Decisions, Lawrence Erlbaum Associates, Mahwah, NJ, 2005.

6. Abraham, A., Morgan, G., Muir, B. and Duffy, P., Part A: Implementing Best Practice Recommendations For Coach Development Within a Higher Education Setting: The Leeds Metropolitan University M.Sc. in Sport Coaching; Part B: Understanding Governing Body Readiness for Level 4: A Qualitative Examination, Sports Coach UK, Leeds, 2011. 
7. Abraham, A., Morgan, G. and North, J., Task Analysis of Coach Developers: Applications to The FA Youth Coach Educator Role, in: Chaudet, H., Pellegrin, L. and Bonnardel, N., eds., Proceedings of the 11th International Conference on Naturalistic Decision Making (NDM 2013), 2013, 21-24, Available from: http://www.ndm11.org/proceedings/papers/ndm11-175.pdf

8. Biggs, J.B., Enhancing Teaching Through Constructive Alignment, Higher Education, 1996, 32, 347-364.

9. Lyle, J., Abraham, A., Morgan, G. and Muir B., UKCC Level 4 Guidance Document, Sports Coach UK, Leeds, 2010.

10. Abraham, A., Muir, B. and Morgan, G., UK Centre for Coaching Excellence Scoping Project Report: National and International Best Practice in Level 4 Coach Development, Sports Coach UK, 2010.

11. Shulman, L.S., Those Who Understand: Knowledge Growth in Teaching, Educational Research, 1986,15(3),4-14.

12. Côté, J. and Gilbert, W., An Integrative Definition of Coaching Effectiveness and Expertise, International Journal of Sports Science and Coaching, 2009, 4(3), 307-323.

\section{EDITOR'S NOTE}

Andy Abraham is a Principal Lecturer in Sport Coaching at Leeds Beckett University. He has 17 years experience in researching coaching and coach education. He has been involved in writing numerous degrees and postgraduate qualifications in the area of sport coaching and coach education. Most recently he has been engaged in researching and creating a bespoke postgraduate qualification in coach education for the Football Association (FA). 